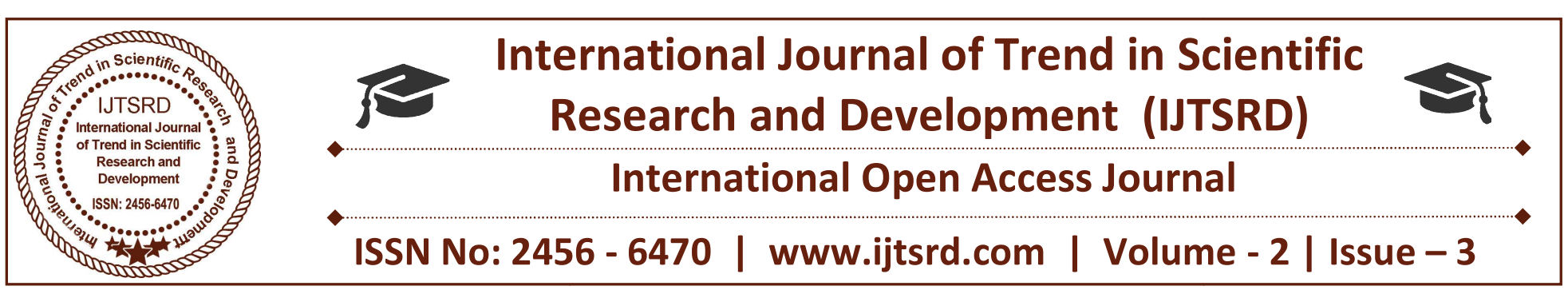

\title{
Comparative Evaluation of Mechanical Characterization Features of Dissimilar Weldments
}

\author{
Ankur Sethi \\ Assistant Professor, GTB Group of Institution, \\ Chhapianwali, Malout, Punjab, India
}

\author{
Rutash Mittal \\ Assistant Professor, Malout Institute of Management \\ and Information Technology, Malout, Punjab, India
}

\begin{abstract}
An attempt has been prepared to join the two dissimilar materials AISI 310 and AISI 316 L by Tungsten Inert Gas (TIG) welding process. AISI $316 \mathrm{~L}$ and $90 \mathrm{~S}$ was used as filler metal. The microstructures of AISI 316 L and AISI 310 were evaluated after the TIG welding. And also various mechanical tests were conducted on Weldments to evaluate the mechanical properties .In this paper, the focus is purely on characterization and analysis of the dissimilar metal welded joint. The chemical composition of base metals as well as filler metals was found to play an important role on mechanical properties. Mechanical tests such as SEM/EDS, optical micro-structure, micro-hardness, tensile test and fractrography are performed. And then a comparison is made between the results
\end{abstract}

Keywords: Dissimilar metal weld, TIG welding, AISI 310 and AISI $316 \mathrm{~L}$

\section{INTRODUCTION}

Welding is one of the most effective joining process employed in wide range of industrial application for joining of materials [1]. The dissimilar metal welded joints have been emerged as a structural material for various metallurgical and industrial applications which provides improved combination of mechanical properties like corrosion resistance, strength with lower cost. Selections of joining process for such a materials are very difficult because of their physical and chemical properties [5]. Dissimilar metal Weldments are generally used in various industries such as power generation, metallurgical, chemical industry, electronics, boiler manufacturing and nuclear industries to take the benefit by combining the properties of different materials in a single component [2]

The reported work have been described that there are many parameters that control the weld ability of dissimilar metals such as their crystal structure, chemical composition, solubility in the liquid and solid state. Spreading of filler metal in the weld pool area frequently leads to the creation of inter-metallic phases. Many of these inter-metallic phases are brittle and hard and affect the ductility of joint, mechanical strength of the joint and toughness.

Tungsten inert gas welding is a joining process and it can be wildly used in modern industries for joining either similar or dissimilar metal Weldments. Tungsten inert gas welding is often known as gas tungsten arc welding (GTAW) .The advantages of tungsten inert gas welding like joining of similar and dissimilar metals at very high quality weld, low heat affected zone, absence of slag etc. Gas tungsten arc welding wildly uses a non-consumable tungsten electrode to produce the weld because it created a very high temperature to weld the metals. Weld zone is protected by a shielding gas (usually inert gas such as argon) from atmospheric air or gases and a filler material is normally used for fill the gap of metal [3].

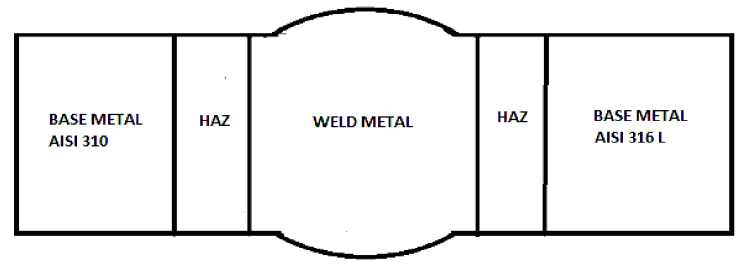

Fig:-1 Schematic diagram of welded joint. 


\section{Experimental:}

In this research the dissimilar metal welding between AISI 310 and AISI 316 L was carried out by using TIG welding process with two different filler metals. The base metal used for dissimilar welding were AISI 310 and AISI $316 \mathrm{~L}$ and thickness of base metals were $4 \mathrm{~mm}$. AISI 316L and $90 \mathrm{~S}$ was used as filler metal. The chemical compositions of base metal and filler metals are shown in Tables 1 and 2, respectively

Table 1: Crhemical Composition of Base Metal

\begin{tabular}{|l|c|c|c|c|c|c|c|c|}
\hline $\begin{array}{l}\text { Element } \\
\text { Material }\end{array}$ & $\mathrm{C}$ & $\mathrm{S}$ & $\mathrm{P}$ & $\mathrm{Si}$ & $\mathrm{Mn}$ & $\mathrm{Ni}$ & $\mathrm{Cr}$ & $\mathrm{Mo}$ \\
\hline $\begin{array}{l}\text { AISI } \\
\text { 316L }\end{array}$ & 0.040 & 0.010 & 0.025 & 0.520 & 1.79 & 19.010 & 24.700 & -- \\
\hline $\begin{array}{l}\text { AISI } \\
\text { 310 }\end{array}$ & 0.020 & 0.010 & 0.040 & 0.250 & 1.30 & 10.260 & 16.420 & 2.100 \\
\hline
\end{tabular}

Table 2: Chemical Composition of Filler Metal

\begin{tabular}{|l|l|l|l|l|l|l|l|l|l|l|l|}
\hline Elemellt & $\mathrm{C} \%$ & $\mathrm{Min} \%$ & $\mathrm{Si}^{2} \%$ & $\mathrm{Cr}^{0} \%$ & $\mathrm{Ni} \%$ & $\mathrm{M} 0 \%$ & $\mathrm{~N} \%$ & $\mathrm{~V} \%$ & $\mathrm{Cu} \%$ & $\mathrm{~S} \%$ & $\mathrm{P} \%$ \\
\hline $316 \mathrm{~L}$ & 0.020 & 1.450 & 0.350 & 19.100 & 11.720 & 2.240 & -- & --- & 0.100 & 0.017 & 0.027 \\
\hline $90 \mathrm{~S}$ & 0.084 & 0.520 & 0.460 & 2.420 & 0.020 & 0940 & -- & 0.001 & 0.220 & 0.005 & 0.011 \\
\hline
\end{tabular}

Metallurgical investigations of the joint were done after polishing the weld samples. The samples were prepared by first cutting in appropriate size by wire cut machine and then grinding using 80,120, 400, 800, $600,1000,1500$ and 2000 grits of emery papers and final polishing is done by using $0.5 \mu \mathrm{m}$ diamond powder. Optical microstructure was measured along a straight line starting from first base metal, HAZ, weld metal, HAZ and ends at second base metal by an optical-microscope and a scanning electron microscope equipped with an energy dispersion $\mathrm{X}$ Ray spectrometer (SEM/EDS). And micro hardness of all three specimens is measure by micro-vicker hardness testing machine. The mechanical properties of the welded joint were analyzed by conducting various tests. The tensile test was performed at a crosshead speed of $3 \mathrm{~mm} / \mathrm{min}$. The shape of the specimens which were used for performing tensile tests was dumbled shape and the length was $200 \mathrm{~mm}$ and width was $20 \mathrm{~mm}$ as shown in fig: 2 .

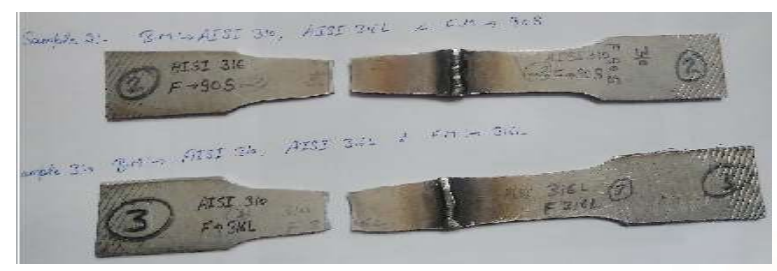

Fig: 2: Tensile Tested specimens

\section{RESULT AND DISCUSSIONS:}

For microstructure observations, the welded samples were cut right angle to the welding direction from the welded joints and after cutting the samples in small pieces then polished and etched by using a kroll solution. Optical micro-scope was used to observe the microstructure of the weld interface. Scanning electron microscope (SEM) was used to observe the microstructure, element distribution and fracture analysis.

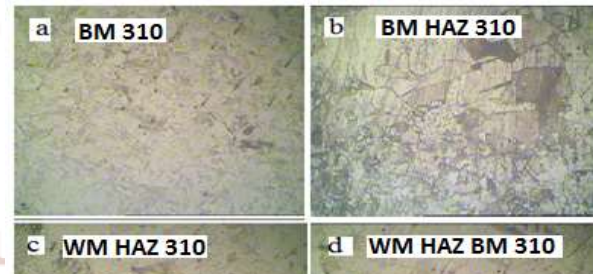

Fig 3. Optical micro-structure of sample 1 AISI 310 and AISI 316L welded by filler Metal AISI $316 \mathrm{~L}$

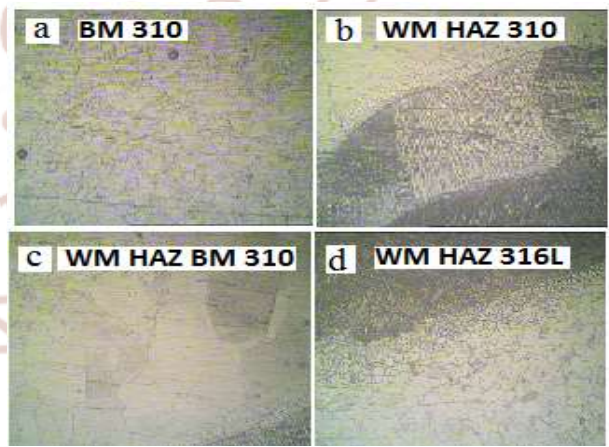

Fig 4. Optical micro-structure of sample 2 AISI 310 and AISI $316 \mathrm{~L}$ welded by filler metal $90 \mathrm{~S}$

MICROHARDNESS: Hardness measurements of specimens were performed by means of Vickers method along the straight line starting from first base metal, haz, wm, haz, and then second base metal. Hardness results of all the samples are shown in table 3 . In sample 1 the hardness values are lies in the range of 145-160, for sample 2 hardness values lies in the range of 152-458. 


\begin{tabular}{|c|c|c|}
\hline \multicolumn{3}{|c|}{ Micro-Hardness } \\
\hline $\begin{array}{l}500 \\
400 \\
300 \\
200\end{array}$ & & - \\
\hline & Sample 1 & Sample 2 \\
\hline BM 310 & 160 & 156 \\
\hline - HAZ 310 & 149 & 152 \\
\hline WM & 152 & 458 \\
\hline HAZ 316 & 145 & 156 \\
\hline BM 316 & 149 & 156 \\
\hline
\end{tabular}

Table: 3. Shows comparison of micro-hardness of samples

TENSLIE TEST: A tensile test is the most common type mechanical test we can perform to predict the ultimate tensile strength of specimen. A tensile test is fully standardized, simple and less expensive. By pulling on something, you will very quickly determine how the material will react to forces being applied in tension. By pulling material, you will find its strength along with how much it will elongate. One of the properties you can determine about a material is its ultimate tensile strength. This is the maximum load the specimen sustains during the test. The ultimate tensile strength may or may not equate to the strength at break. This all depends on what type of material you are testing brittle, ductile or a substance that even carries both properties. The test process involves placing the test specimen in the machine and applying tension to it until it fractures. [4]

Tensile test of the samples were done on universal testing machine and the ultimate tensile strength of samples are shown in the fig: 6

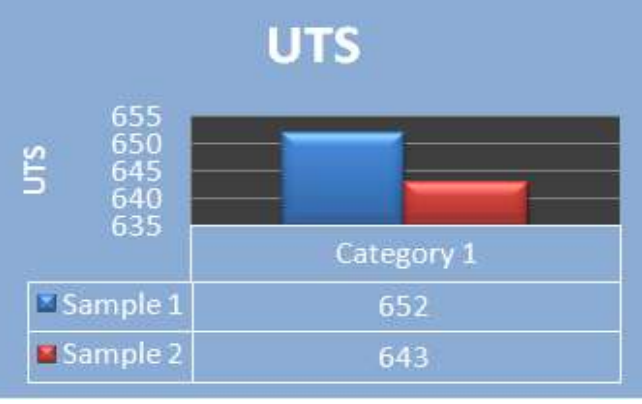

Table: 4.Ultimate tensile strength of samples.

Ultimate tensile strength of all the samples is lies in the range of 643-652.

SEM/EDS: Figure 5 shows an SEM (Scanning electron micro-scope) images at the joint interface of the sample 1 and 2 at magnification level of x33, x33 and $\mathrm{x} 35$ respectively. The composition of $\mathrm{Cr}, \mathrm{Fe}$ and Ni were observed in interface by EDS.

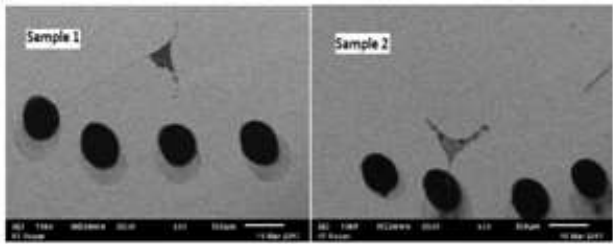

Figure 5. SEM of sample 1 and 2

Sample 1 AISI 310 AISI 316L AISI 316L.

Table: 5. EDS of sample 1

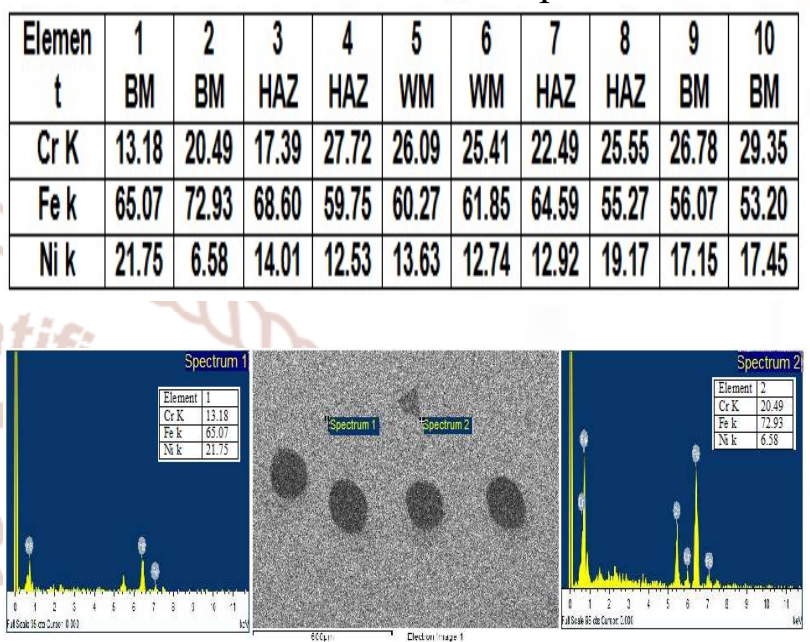

Sample 2: AISI 31090 s AISI 316L

Table: 6 . EDS of sample 2

\begin{tabular}{|c|c|c|c|c|c|c|c|c|c|c|}
\hline $\begin{array}{l}\text { Elem } \\
\text { ellt }\end{array}$ & $\begin{array}{l}1 \\
\mathrm{BM}\end{array}$ & $\begin{array}{l}2 \\
\mathrm{BMI}\end{array}$ & $\begin{array}{l}3 \\
\mathrm{HAZ}\end{array}$ & $\begin{array}{l}4 \\
\mathrm{HAZ}\end{array}$ & $\begin{array}{l}5 \\
\text { WM }\end{array}$ & \begin{tabular}{|l}
6 \\
WM
\end{tabular} & HAZ & \begin{tabular}{|l}
8 \\
HAZ
\end{tabular} & $\begin{array}{l}9 \\
\text { BM }\end{array}$ & $\begin{array}{l}10 \\
\text { BM }\end{array}$ \\
\hline $\mathrm{CrK}$ & 19.63 & 18.68 & 26.80 & 8.76 & 8.47 & 12.44 & 9.07 & 9.98 & 26.72 & 27.31 \\
\hline $\mathrm{FeK}$ & 80.37 & 69.26 & 73.20 & 91.24 & 91.53 & 87.56 & 90.93 & 90.02 & 53.88 & 59.64 \\
\hline $\mathrm{NiK}$ & 0.00 & 12.06 & 0.00 & 0.00 & 0.00 & 0.00 & 0.00 & 0.00 & 19.40 & 13.05 \\
\hline
\end{tabular}

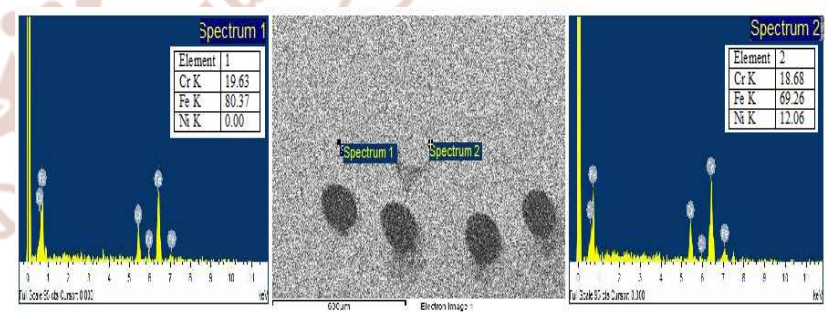

Fracture surface examination: Scanning electron microscopy (SEM/EDS) photographs of fractured surface of tensile tested samples normally show the overall micro-cracks, the striation, as well as beach marks in the fractured region, and the dimples in the ductile fracture region. SEM/EDS photos of samples are shown below in fig. 8 .

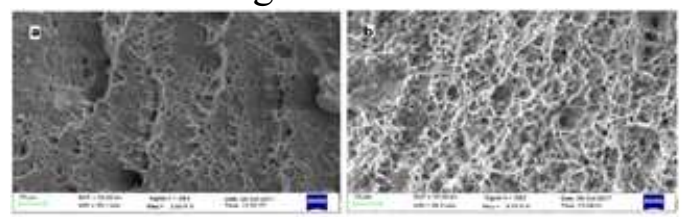

Figure 6: figure $\mathrm{a}$ and $\mathrm{b}$ shows SAM sample 1 and 2 
EDS: Sample 1310 316L 316L (310 left side fracture piece)

\begin{tabular}{|l|l|l|l|l|l|l|l|}
\hline Element & $\mathbf{1}$ & $\mathbf{2}$ & $\mathbf{3}$ & $\mathbf{4}$ & $\mathbf{5}$ & $\mathbf{6}$ & $\mathbf{7}$ \\
\hline $\mathrm{C} \mathrm{K}$ & $\mathbf{1 3 . 6 8}$ & 11.27 & $\mathbf{1 1 . 2 8}$ & $\mathbf{2 9 . 2 4}$ & $\mathbf{2 6 . 2 9}$ & $\mathbf{2 7 . 8 5}$ & $\mathbf{1 3 . 0 5}$ \\
\hline O K & 3.77 & $\mathbf{5 . 6 1}$ & $\mathbf{3 . 6 3}$ & $\mathbf{1 4 . 9 8}$ & 11.26 & $\mathbf{1 5 . 5 1}$ & $\mathbf{2 9 . 0 8}$ \\
\hline $\mathrm{Cr} \mathrm{K}$ & 23.54 & 26.31 & 27.11 & 20.91 & 22.83 & $\mathbf{2 3 . 1 4}$ & $\mathbf{1 . 8 8}$ \\
\hline Fe K & $\mathbf{4 6 . 4 0}$ & $\mathbf{4 5 . 7 4}$ & $\mathbf{4 6 . 0 8}$ & 27.59 & $\mathbf{3 0 . 7 2}$ & $\mathbf{2 8 . 0 0}$ & $\mathbf{4 2 . 1 8}$ \\
\hline $\mathrm{Ni} \mathrm{K}$ & $\mathbf{1 2 . 6 0}$ & 11.07 & $\mathbf{1 1 . 8 9}$ & $\mathbf{7 . 2 7}$ & $\mathbf{8 . 9 0}$ & $\mathbf{5 . 5 0}$ & $\mathbf{1 3 . 8 1}$ \\
\hline
\end{tabular}
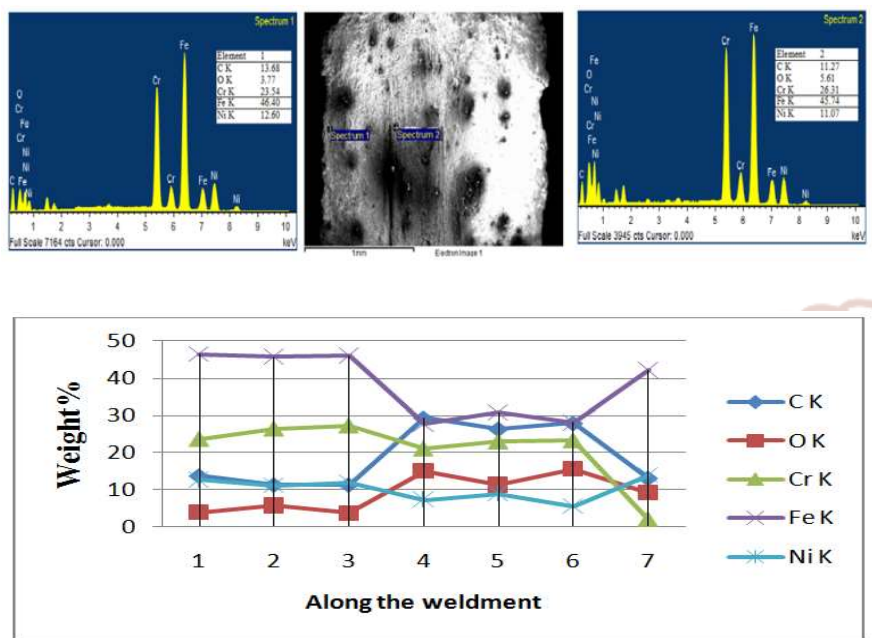

EDS: Sample 231090 S 316L (316L Right side fracture piece)

\begin{tabular}{|l|l|l|l|l|l|l|l|}
\hline Element & 1 & 2 & 3 & 4 & 5 & 6 & 7 \\
\hline CK & 34.25 & 32.88 & 26.51 & 53.12 & 34.42 & 20.88 & 40.19 \\
\hline OK & 13.75 & 17.78 & 12.73 & 34.78 & 8.12 & 44.93 & 18.24 \\
\hline CrK & 9.40 & 8.85 & 10.82 & 2.00 & 11.97 & 6.32 & 7.46 \\
\hline FeK & 36.01 & 34.38 & 42.36 & 7.19 & 39.28 & 23.71 & 28.56 \\
\hline NiK & 5.22 & 4.78 & 5.76 & 0.77 & 4.00 & 2.87 & 4.08 \\
\hline Mo L & 1.37 & 1.33 & 1.81 & 2.14 & 2.22 & 1.29 & 1.48 \\
\hline
\end{tabular}
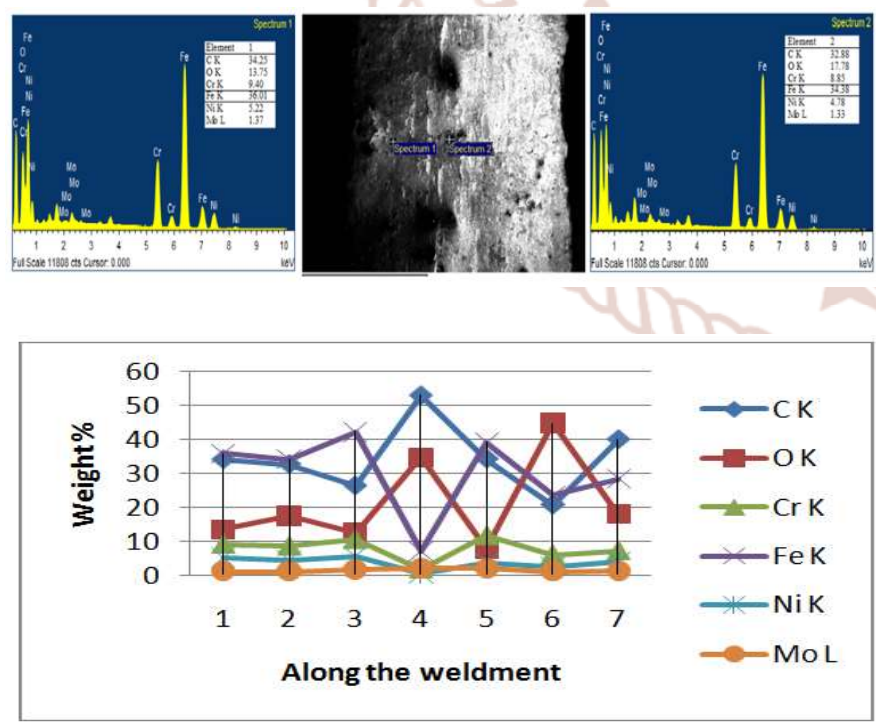

\section{CONCLUSION:}

Dissimilar material welding was done between AISI 316 L and AISI 310 with TIG welding using two different filler material AISI $316 \mathrm{~L}$ and $90 \mathrm{~S}$ and mechanical properties are evaluated by conducting various tests and it is concluded that;
1. The filler metal AISI $316 \mathrm{~L}$ is better as comparative to $90 \mathrm{~S}$ because the sample 1 which contains AISI $316 \mathrm{~L}$ as a filler metal shows high value of tensile strength in tensile test.

2. Hardness test reveals that improved values compared to $90 \mathrm{~S}$ because of relatively high values of micro hardness in HAZ and $\mathrm{WM}$ region of sample containing $90 \mathrm{~S}$ as a filler metal.

3. Micro-structure of HAZ and WM of sample 1 containing AISI $316 \mathrm{~L}$ as a filler metal shows that inter metallic combination filler metal and weld metal is sound.

4. Chemical Composition of Filler Metal $316 \mathrm{~L}$ is also better because it contain large amount of $\mathrm{Cr}$, $\mathrm{Ni}$ and Mo.

Thus it is concluded that filler metal AISI $316 \mathrm{~L}$ is better as comparative to filler metal $90 \mathrm{~S}$.

\section{REFFERENCES:}

1. R. Nivas, P.K singh, G. Das, S.K Das, S. Kumar, B. Mahato, K. Sivaparasada and M.Ghosh (2017), "A comparative study on micro-structre and mechanical properties near interface for dissimilar materials during conventional v-grooveand narrow gap welding." Journal of manufacturing processes vol. 25 pp.224-28.

2. Sajjad gholami shiri, Mohsen nazarzadeh, Mahmood sharifitanar, Mehdi shafiee afarani (2012), " Gas tungsten arc welding of cp- copper to 304 ss using different filler meterials", Trans. Nonferrous met. Soc. China 22, pp 2937-2942.

3. Prashant. K. S, Pnakaj. K, Baljeet. S, Rahul. K.S, (2015), " A review on TIG welding for optimizing process parameters on dissimilar joints." International journal of engineering research and applications, ISSN : 2248-9622 vol. 5, issue 2, pp.125-128.

4. Ravinder , S.K. Jarial, (2015), "Parametric optimization of TIG welding on stainless steel (202) and mild steel by using taguchi method", International journal of enhanced research in science technology and engineering, vol.4 issue. 6 pp:484-494.

5. Radha raman mishra, visnu kumar tiwari and rajesha, (2014), " A study of tensile strength of MIG and TIG welded dissimilar joints of mild steel and stainless steel", International journal of advances in materials science and engineering vol.3 